\title{
Unsaturated Heteropolyoxotungstates with Platinum Cation Complexation
}

\author{
Grama Lavinia1', Muntean Daniela-Lucia², Curticăpean A1 \\ 1 Department of General and Inorganic Chemistry, Faculty of Pharmacy, University of Medicine and Pharmacy, Tîrgu Mureș, Romania \\ 2 Department of Analytical Chemistry and Drugs Analysis, Faculty of Pharmacy, University of Medicine and Pharmacy, Tîrgu Mureș, Romania
}

\begin{abstract}
Background: Polyanions are a special category of coordination compounds with a large development in last years. By coordination of metal oxoions at the lacunary polyoxometalates are obtained new compounds which are studied for theirs possible antitumoral and antiviral activities. The polyoxometalates can bind cations by oxygen atoms from their saturated surface structure or by embedding in vacant sites.

Material and method: The methods used for determining cation coordination with the unsaturated polyoxotungstate are spectrophotometry and conductometry. The solutions used in this study were: for ligand a solution of $\mathrm{K}_{27}\left[\mathrm{KAsW}_{40} \mathrm{O}_{140}\right]$ and for cation a solution of $\mathrm{K}_{2}[\mathrm{PtCl} 6]$. The variation of electrical conductivity of ionic species found in solution, caused by their concentrations, decreases during the complex formation, which was determined by conductometry. The spectrophotometric assay was performed to verify ratios between cation:ligand combination, determined by conductometry.

Results: The graphical representations of conductivity function of number of moles of added titrant solutions emphasize that there are two types of coordination compounds with two different combination ratios ligand:cation at 1:2 or 1:4. The spectrophotometric determination performed, confirmed these ratios.

Conclusions: There are two types of coordination complexes, and the ligand:cation ratios are well known for encrypting polyoxotungstates type used in the study. Besides the main active position SC where $\mathrm{K}^{+}$alkaline cation is coordinated, it has four active stand side $\mathrm{S}_{1-4}$, which
\end{abstract} can coordinate metal cations, depending on the size of their cationic radius and the electronic charge they hold.

Keywords: polyoxometalates, coordination, $\mathrm{Pt} 4+$

Received: 13 April 2012 / Accepted: 7 October 2013

\section{Introduction}

The polyoxometalates is a class of macromolecular inorganic coordination compounds, obtained by polycondensation of elements oxoions with general formula $\left[\mathrm{X}_{\mathrm{x}} \mathrm{M}_{\mathrm{m}} \mathrm{O}_{\mathrm{y}}\right]^{\mathrm{q}}$ They are assemblies of polyhedra containing inside the $\mathrm{X}$ heteroatom (primary or secondary) and the $\mathrm{M}$ addenda atoms (transition metals, hexacoordinated). The structure is delimited by oxygen atoms, with low basicity, relatively inactive, which does not favor further polymerization. This is the key for stability of these compounds $[1,2]$.

The polyoxotungstates are a subdivision of this class, where the addenda atom $\mathrm{M}$ is represented by $\mathrm{W}$. Basic element of structure is the $\mathrm{WO}_{6}$ octahedron coordinated around the $\mathrm{XO}_{\mathrm{p}}$ heteroatoms (Figure 1a and $1 \mathrm{~b}$ ).

These compounds have saturated or unsaturated structures obtained by removing one or several $\mathrm{WO}_{6}$ octahedrons. The unsaturated polyoxometalates are a special category of coordination compounds because of their physical and chemical properties, based on unsaturated structures [3]. The terminal oxygen atoms from their structures give them a high coordinative capacity for many cations $[4,5]$. After coordination, the structures do not change; only litthe displacements of atoms occur. Depending on the degree of unsaturated structures, in lacunae, a high density

Correspondence to: Lavinia Grama

E-mail: grama.lavinia@yahoo.com of electrons appears. The research of coordination between metal oxoions and lacunary polyoxometalate compounds is very important for their antitumoral and antiviral activity $[6,7]$.

The typical structures (with W and Mo) used for obtaining lacunary species (mono to three lacunae) are $\alpha$-Keggin $\left[\mathrm{XM}_{12} \mathrm{O}_{40}\right]^{\text {n- }}$ and $\alpha$-Dawson-Wells $\left[\mathrm{X}_{2} \mathrm{M}_{18} \mathrm{O}_{62}\right]^{\text {n- }}$ (Figure 2).

In coordination with transition cations, lacunary polyoxometalates are working as polydentate ligands. The transition metals are small enough for being embedded in the lacunary sites [8]. After coordination, monomers or dimers with unchanged spatial structure are obtained. By removing one triplet from the Keggin or Dawson structure, three lacunary ligands are obtained: $\mathrm{B}-\left[\mathrm{PW}_{9} \mathrm{O}_{34}\right]^{9-}$ and $\left[\mathrm{P}_{2} \mathrm{~W}_{15} \mathrm{O}_{56}\right]^{12-}$ and they can work as heptadental ligands. They can coordinate metal cations by six terminal oxygen atoms from six $\mathrm{WO}_{6}$ octahedra and the terminal oxygen that is not common with the central heteroatom $[4,9,10]$.

The physico-chemical methods used for determining coordination between transition cations and unsaturated polyoxometalates follow their formation and stabilities for the ratio between cation and ligand. These methods are: conductometry, photocolorimetry, chromatography, and electrophoretic methods $[11,12,13]$.

The domain of $\mathrm{pH}$ stability is between 4 and 8 . If the solution is acidified, the unsaturated structures return to the saturated forms $\mathrm{XW}_{12}$ and $\mathrm{X}_{2} \mathrm{~W}_{18}$. 


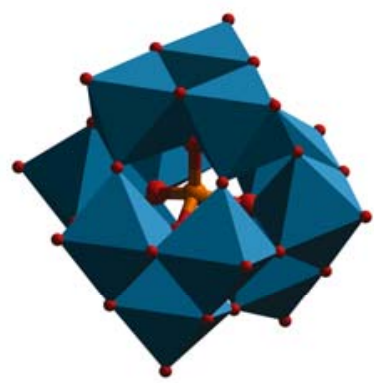

a

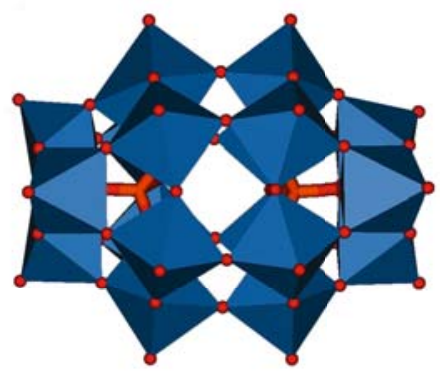

b
Fig. 1. Saturated polyoxometalates structures. a. $\alpha$-Keggin $\left[\mathrm{XM}_{12} \mathrm{O}_{40}\right]^{\text {n- }}$ b. $\alpha$-Dawson-Wells $\left[\mathrm{X}_{2} \mathrm{M}_{18} \mathrm{O}_{62}\right]^{\mathrm{n}-}$

The coordination of $\mathrm{Pt}^{4+}$ to polyoxotungstate $\left[\mathrm{KAs}_{4} \mathrm{~W}_{40} \mathrm{O}_{140}\right]^{27-}$ (Figure 3), and the determination of the combination ratios (by conductometry and spectrophotometry) between them, are presented.

\section{Materials and methods}

The physico-chemical methods used for determining the ratio between free cation and unsaturated polyoxometalates for their coordination, follow their formation and stabilities. The methods used for determining cation coordination with the unsaturated polyoxotungstate are spectrophotometry and conductometry.

The solutions used in this study were: for ligand a solution of $\mathrm{K}_{27}\left[\mathrm{KAsW}_{40} \mathrm{O}_{140}\right]$ and for cation a solution of $\mathrm{K}_{2}\left[\mathrm{PtCl}_{6}\right]$.

The variation of electrical conductivity of ionic species found in solution, caused by their concentrations, decreases during the complex formation, which was determined by conductometry. Different ligand concentrations, $10^{-5}$ $\mathrm{M}, 2^{*} 10^{-5} \mathrm{M}$, and $5^{*} 10^{-5} \mathrm{M}$ were used. The basic solution was prepared by dissolving $0.0585 \mathrm{~g} \mathrm{~K}_{27}\left[\mathrm{KAsW}_{40} \mathrm{O}_{140}\right]$ in $100 \mathrm{~mL}$ distilled water. By dissolving $1 \mathrm{~g} \mathrm{~K}_{2}\left[\mathrm{PtCl}_{6}\right]$ in 50 $\mathrm{mL}$ warm water, the solution $4.1^{*} 10^{-2} \mathrm{M}$ was obtained. With these solutions, three series of determinations were carried out. For the first series of determinations, $40 \mathrm{~mL}$ of $10^{-5} \mathrm{M}$ ligand solution was titrated with $4 \mu \mathrm{L} 4.1^{*} 10^{-2} \mathrm{M}$ $\mathrm{K}_{2}\left[\mathrm{PtCl}_{6}\right]$ solution each time. The second series was made

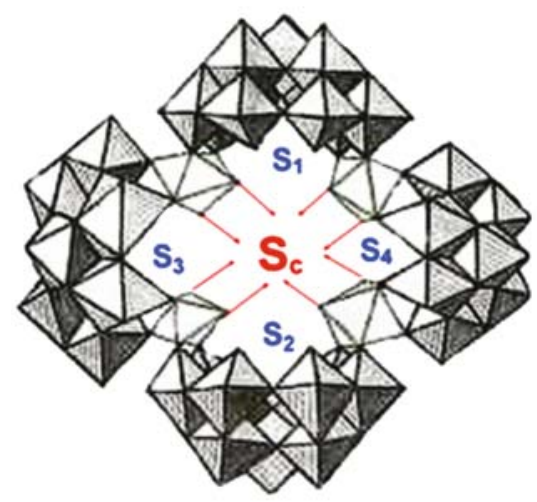

Fig. 3. The spatial structure of polyoxoarseno tungstate cryptand $\left[\mathrm{KAs}_{4} \mathrm{~W}_{40} \mathrm{O}_{140}\right]^{27-}$

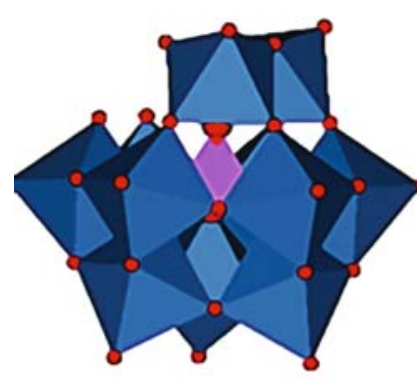

a

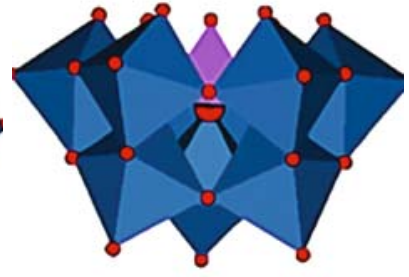

b
Fig. 2. The unsaturated Keggin structures. a. Mono lacunary

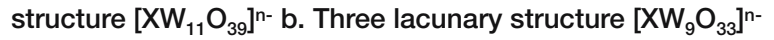

from $40 \mathrm{~mL}$ of $2^{*} 10^{-5} \mathrm{M}$ ligand solution, and titrated with $8 \mu \mathrm{L} 4.1^{*} 10^{-2} \mathrm{M} \mathrm{K}_{2}\left[\mathrm{PtCl}_{6}\right]$ solution, and the third series of determination by titrating $20 \mu \mathrm{L} 4.1^{*} 10^{-2} \mathrm{M} \mathrm{K}_{2}\left[\mathrm{PtCl}_{6}\right]$ solution in $40 \mathrm{~mL} 5^{*} 10^{-5} \mathrm{M}$ ligand solution. Measurements were performed using an Innolab 740 multiparameter.

The spectrophotometric assay was performed to verify ratios between cation:ligand combination, determined by conductometry. The determinations were made with UVVIS AnalytikJena SPECORD 210 spectrophotometer by 1:10 diluted solutions (for all concentrations) of ligand and 1:1000 diluted solution for the platinum cation.

\section{Results}

Results obtained by conductometry are presented in Figure 4 , representing the conductivity values depending on the

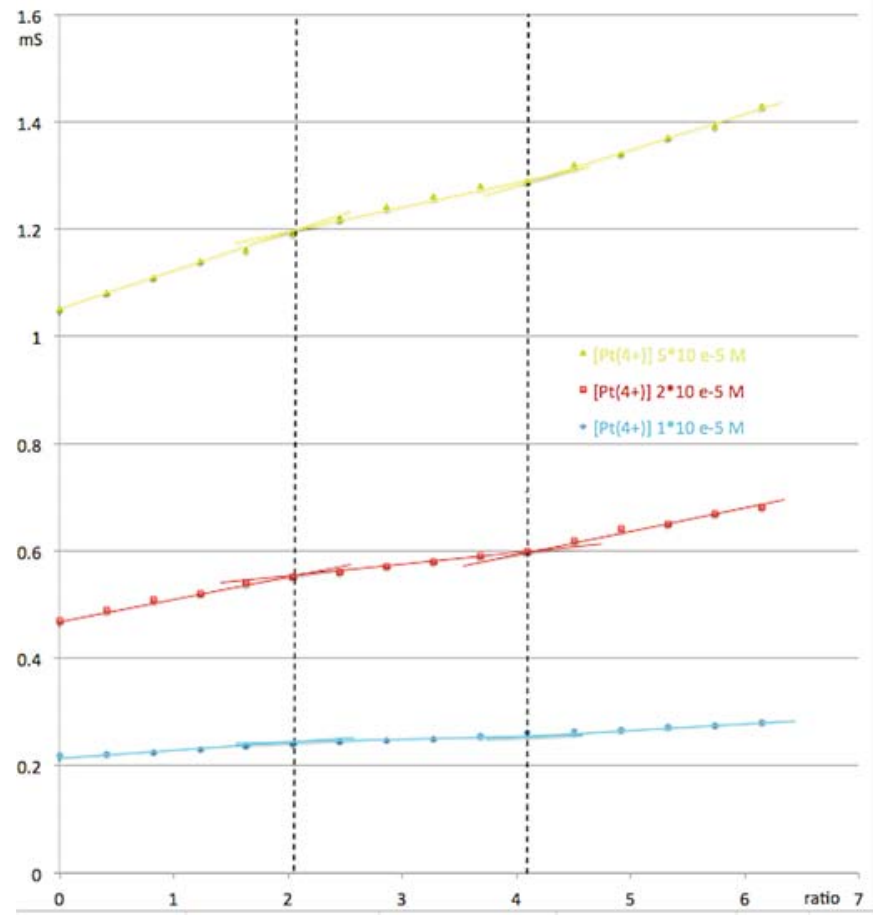

Fig. 4. The dependence of conductivity on the moles number for all the three series. Series 1: $40 \mathrm{~mL}$ ligand solution $10^{-5} \mathrm{M}$ and $4 \mu \mathrm{L}$ cationic solution $\mathrm{K}_{2}\left[\mathrm{PtCl}_{6}\right] 4.1^{*} 10^{-2} \mathrm{M}$. Series 2: $40 \mathrm{~mL}$ ligand solution $2^{*} 10^{-5} \mathrm{M}$ and $8 \mu \mathrm{L}$ cationic solution $\mathrm{K}_{2}\left[\mathrm{PtCl}_{6}\right] 4.1^{*} 10^{-2} \mathrm{M}$. Series 3: $40 \mathrm{~mL}$ ligand solution $5^{\star} 10^{-5} \mathrm{M}$ and $20 \mu \mathrm{L}$ cationic solution $\mathrm{K}_{2}\left[\mathrm{PtCl}_{6}\right] 4.1 * 10^{-2} \mathrm{M}$ 


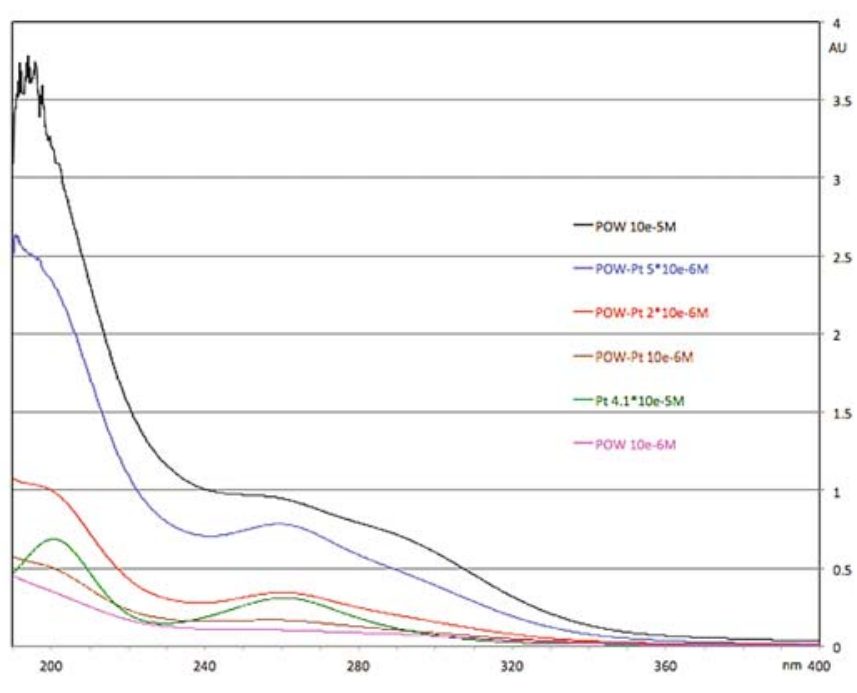

Fig. 5. The overlaid recorded spectra for all coordinative compounds and for the starting solutions of polyoxotungstate and platinum cation solution

moles number from the added titrant solution. Figure 5 shows the overlaid spectrophotometric results.

\section{Discussions}

The graphical representation of conductivity depending on the number of moles of added titrant solution shows the appearance on each graphic of two points of equivalent. The first point corresponds to a 1:2 ratio of polyoxotungstate:cation, and the second to a $1: 4$ ratio of polyoxotungstate:cation, respectively.

The spectral results verified these coordination ratios for ligand:cation complexes. The ligand absorption maxima value changing from $190 \mathrm{~cm}^{-1}$ to $195 \mathrm{~cm}^{-1}$ for the $\mathrm{W}=\mathrm{O}$ bond, and from $250 \mathrm{~cm}^{-1}$ to $260 \mathrm{~cm}^{-1}$ for the W-O-W bond. The amplitude of these points is shifting.

\section{Conclusions}

Graphical representations of conductivity depending on the molar ratio dependence of $\mathrm{POW} \mathrm{Pt}^{+4}$ and spectra, highlight the formation of two types of coordination complexes - for ligand:cation ratios of 1:2 and 1:4.
These ratios are well known for encrypting polyoxotungstates type used in the study. Besides the main active position $\mathrm{SC}$ where $\mathrm{K}^{+}$alkaline cation is coordinated, it has four active stand side $S_{1-4}$, which can coordinate metal cations, depending on the size of their cationic radius and the electronic charge they hold.

\section{Acknowledgement}

This paper is partly supported by the Sectorial Operational Programme Human Resources Development (SOP HRD), financed from the European Social Fund and by the Romanian Government under the contract number POSDRU 80641.

\section{References}

1. Marcu GH. Heteropolioxometalați, Chimia polioxometalaților. Ed.Tehnică 1997;

2. Pope MT, Muller A. Polyoxometalate Chemistry: An Old Field with New Dimensions in Several Disciplines. Angew. Chem. 1991;103:56-70.

3. De-Liang L, Tsunashima R, Cronin L. Polyoxometalates: Building Blocks for Functional Nanoscale Systems. Angew. Chem. Int. Ed. 2010; 49:1736 -1758;

4. Souchay P. Polyanions et Polycations. Gauthier-Villars, Paris, 1963, 64.

5. Putaj P, Lefebvre F. Polyoxometalates containing late transition and noble metal atoms. Coordination Chemistry Reviews 225, 2011, 1642-1685;

6. Zhai F, Li D, Zhang C, Wang X, Li R. Synthesis and characterizationof polyoxometalates loaded starch nanocomplex and its antitumoral activity. European J. Medicinal Chemistry. 2008;43:1911-1917.

7. Liu YN, Shi S, Mei WJ, et al. In vitro and in vivo investigations on the antiviral activity of a series of mixed-valence rare earth borotungstate heteropoly blues. European J. of Medicinal Chemistry. 2008;43:1963-1970.

8. Lis S. Applications of spectroscopic methods in studies of polyoxometalates and their complexes with lanthanide(III) ions. J. Alloys and Compounds. 2000;300-301:88-89.

9. Muller A, Reuter H, Dillinger S. Supramolecular Inorganic Chemistry: Small Guests in Small and Large Hosts. Angew.Chem.Int.Ed.Engl. 1995;34:2328-2361.

10. Yan B, Li YF, Zhao HY, Pan WP, Parkin S. Polyoxometalates functioned as ligands: synthesis and crystal structure of a new hybrid compound constructed from metatungstate and metal complex units. Inorganic Chemistry Comunications. 2009;12:1139-1141.

11. Dușa S. Chimie analitică instrumentală. Ed. University Press, Tîrgu Mureș, 2007.

12. Muntean DL, Imre S. Analiza medicamentului ghid practic. Ed. University Press, Tîrgu Mureș, 2007.

13. Rusu D, Crăciun C. Cercetări fizico-chimice în domeniul polioxometalaților complecși. Casa Cărții de Știință, Cluj-Napoca, 2006. 